\title{
Wpływ pakietu dodatków na właściwości paliwa pozostałościowego w trakcie przechowywania
}

\begin{abstract}
W artykule przedstawiono wyniki badań wybranych parametrów paliw pozostałościowych uszlachetnionych pakietami dodatków po okresie długotrwałego przechowywania w podwyższonej temperaturze. Badane pakiety dodatków zawierały katalizator spalania, dodatek detergentowy lub detergentowo-dyspergujący oraz rozpuszczalnik węglowodorowy. Badania miały charakter porównawczy, tj. wykonywane były dla paliw bazowych i paliw zawierających formulacje dodatków. Test prowadzono w temperaturze $80^{\circ} \mathrm{C}$ w ciągu trzech miesięcy dla dwóch paliw bazowych oraz trzech formulacji pakietów dodatków uszlachetniających. Badania ciężkich olejów opałowych odbywały się w zakresie wybranych parametrów fizykochemicznych, ze szczególnym uwzględnieniem tych, które mogą ulec zmianie pod wpływem dodatków uszlachetniających w trakcie długotrwałego przechowywania, tj. gęstości, lepkości kinematycznej, temperatury płynięcia, liczby rozdziału faz oraz zawartości osadów. Stwierdzono, że nowe formulacje pakietów dodatków do paliw pozostałościowych nie wpływają negatywnie na badane parametry ciężkiego oleju opałowego w trakcie długotrwałego przechowywania w podwyższonej temperaturze. Uszlachetnione paliwa mogą być eksploatowane w warunkach zakładów energetycznych, co eliminuje konieczność wprowadzania skomplikowanych rozwiązań technicznych w instalacjach podawania ciężkiego oleju opałowego, niezbędnych w przypadku dozowania pakietu on-line.
\end{abstract}

Słowa kluczowe: katalizatory spalania, dyspergatory, paliwo pozostałościowe.

\section{Effect of a package of additives on the properties of residual fuel during storage}

The article presents the results of selected parameters of residual fuels improved with a package of additives after long term storage at increased temperature. The test additive packages contained a combustion catalyst, a detergent or a detergentdispersant and a hydrocarbon solvent. The research was comparative, i.e. were conducted for basic fuels and fuels containing additive formulations. The test was conducted at $80^{\circ} \mathrm{C}$ for three months for the two fuels and the three formulations of additive packages. The study of heavy fuel oils were carried out in selected physical and chemical parameters, with particular emphasis on those that can be changed under the influence of additives during long-term storage i.e. the density, kinematic viscosity, pour point, the separability number and the content of sediments. The novel formulations additive packages for residual fuels do not affect the measured parameters of heavy fuel oil during prolonged storage at increased temperature. Improved fuel can be used in power plants conditions - it eliminates the need to introduce complicated technical solutions in heavy fuel oil supply systems, which is indispensable for dosing package on-line.

Key words: combustion catalysts, dispersants, residual fuel.

\section{Wprowadzenie}

Stosowanie ciężkich paliw pozostałościowych wiąże się $\mathrm{z}$ wieloma problemami eksploatacyjnymi, tj. słabą stabilnością, skłonnością do wytrącania osadów i wysoką emisją substancji szkodliwych powstających podczas spalania $[2,3]$. W dotychczasowej praktyce przemysłowej do ciężkich olejów opałowych nie są stosowane dodatki uszlachetniające.
W INiG - PIB przeprowadzono badania nad opracowaniem dodatku poprawiającego stabilność, a także dokonano wstępnej selekcji dodatków pod względem ich działania dyspergującego oraz zapobiegającego wytrącaniu osadów [4]. Wytypowane dodatki zostały wykorzystane do opracowania nowych formulacji pakietów, przeznaczonych do ciężkich olejów opa- 
łowych. Pakiety te, oprócz dodatków stabilizujących, zawierają katalizatory spalania, których stosowanie ma zapewnić ograniczenie emisji substancji szkodliwych powstających podczas spalania, a także zmniejszenie zużycia paliwa [12, 13]. Wpływ metaloorganicznych dodatków do olejów napędowych na emisję spalin i zużycie paliwa w silnikach z zapłonem samoczynnym jest szeroko omawiany w literaturze światowej $[1,5,6,7-10]$. Analogicznego działania można się spodzie- wać w przypadku ich zastosowania do olejów opałowych, w tym również ciężkich paliw pozostałościowych.

Nowe formulacje opracowanych pakietów dodatków do paliw pozostałościowych wymuszają konieczność przeprowadzenia badań ich wpływu na właściwości paliwa w trakcie długotrwałego przechowywania [11]. Paliwa tego typu są bowiem poddawane cyrkulacji ciągłej w wysokiej temperaturze przez okres kilku miesięcy w zakładach energetycznych.

\section{Część doświadczalna}

\section{Metodyka badań}

Badania paliw prowadzono w zakresie wybranych parametrów fizykochemicznych, ze szczególnym uwzględnieniem tych, które mogą ulec zmianie pod wpływem dodatków uszlachetniających w trakcie długotrwałego przechowywania, tj. gęstości, lepkości kinematycznej, temperatury płynięcia, liczby rozdziału faz oraz zawartości osadów.

Wpływ nowych formulacji dodatków oceniany był w warunkach symulujących warunki przemysłowe u użytkowników, tj. po okresie przechowywania w temperaturze $80^{\circ} \mathrm{C}$, w trakcie trzech miesięcy. Badania miały charakter porównawczy - prowadzone były dla paliwa bazowego i paliw zawierających nowe formulacje dodatków. Metody badań przedstawiono w tablicy 1 .

Tablica 1. Zastosowane metody badań

\begin{tabular}{|l|c|}
\hline \multicolumn{1}{|c|}{ Badana właściwość } & Metoda badawcza \\
\hline $\begin{array}{l}\text { Lepkość kinematyczna } \\
\text { w temperaturze } 100^{\circ} \mathrm{C}\end{array}$ & PN-EN ISO 3104 \\
\hline Gęstość & PN-EN ISO 12185 \\
\hline Temperatura płynięcia & PN ISO 3016 \\
\hline Zawartość siarki & PN-EN ISO 14596 \\
\hline Liczba rozdziału faz & ASTM D 7061 \\
\hline Zawartość osadów & PN ISO 10307 \\
\hline
\end{tabular}

\section{Materialy}

Pakiet dodatków PD1 został opracowany w INiG - PIB według zgłoszenia patentowego P.404521 i zawierał pakiet dodatków Energopak 30A ${ }^{\circledR}$, opracowany przez INiG - PIB i EDF Polska S.A., w skład którego wchodziły modyfikatory spalania, dodatek detergentowy i rozpuszczalnik węglowodorowy.

Pakiet dodatków PD2 został opracowany w INiG - PIB według zgłoszeń patentowych: P.404521 oraz P.412034 i zawierał opisany wyżej pakiet dodatków Energopak $30 \mathrm{~A}^{\circledR}$, a także dodatek detergentowo-dyspergujący A.

Pakiet dodatków PD3 różnił się od PD2 zastosowaniem dodatku detergentowo-dyspergującego $\mathbf{B}$ zamiast dodatku A.
Dodatek detergentowo-dyspergujący A zawierał zasadę Mannicha, otrzymaną według zgłoszenia patentowego P.412034, z formaldehydu, alkilofenolu o masie cząsteczkowej od 200 Da do 260 Da i trietylenotetraaminy, w obecności 2-propanolu.

Dodatek detergentowo-dyspergujący B zawierał modyfikowany alkenylobursztynoimido-amid, uzyskany zgodnie ze zgłoszeniem patentowym P.412034, w reakcji acylowania trietylenotetraaminy bezwodnikiem alkenylobursztynowym o średniej masie cząsteczkowej 1000-1500 daltonów przy zachowaniu stosunku molowego reagentów takiego, że na 1 mol polialkylenopoliaminy przypadają 2 mole bezwodnika alkenylobursztynowego, a otrzymany bisalkenylobursztynoimid poddaje się procesowi termicznego kondycjonowania w temperaturze $50 \div 130^{\circ} \mathrm{C}$.

Dodatki wprowadzano do bazowych ciężkich olejów opałowych, których właściwości przedstawiono w tablicy 2.

Paliwa bazowe charakteryzowały się zróżnicowaną jakością: gęstość zawierała się w przedziale od 915,3 kg/m do $946,6 \mathrm{~kg} / \mathrm{m}^{3}$, lepkość kinematyczna od 10,66 mm²/s do $39,14 \mathrm{~mm}^{2} / \mathrm{s}$, zawartość siarki od 1,05\% $(\mathrm{m} / \mathrm{m})$ do $3,0 \%(\mathrm{~m} / \mathrm{m})$, temperatura płynięcia od $-19^{\circ} \mathrm{C}$ do $-20^{\circ} \mathrm{C}$, liczba rozdziału faz (SN) od 4,0 (paliwo stabilne) do 7,4 (paliwo o średniej stabilności), zawartość osadu całkowitego od 0,01\% $(\mathrm{m} / \mathrm{m})$ do $0,12 \%(\mathrm{~m} / \mathrm{m})$ oraz zawartość osadów potencjalnych od $0,02 \%(\mathrm{~m} / \mathrm{m})$ do $0,16 \%(\mathrm{~m} / \mathrm{m})$.

Tablica 2. Charakterystyka paliw bazowych

\begin{tabular}{|l|c|c|c|}
\hline \multicolumn{1}{|c|}{ Badana właściwość } & Jednostka & PA & PB \\
\hline Gęstość w temperaturze $15^{\circ} \mathrm{C}$ & $\mathrm{kg} / \mathrm{m}^{3}$ & 915,3 & 946,6 \\
\hline $\begin{array}{l}\text { Lepkość kinematyczna } \\
\text { w temperaturze } 100^{\circ} \mathrm{C}\end{array}$ & $\mathrm{mm}^{2} / \mathrm{s}$ & 10,66 & 39,14 \\
\hline Zawartość siarki & $\%(\mathrm{~m} / \mathrm{m})$ & 1,05 & 3,00 \\
\hline Temperatura płynięcia & ${ }^{\circ} \mathrm{C}$ & $-20,0$ & $-19,0$ \\
\hline $\mathrm{SN}$ (liczba rozdziału faz) & - & 7,4 & 4,0 \\
\hline Zawartość osadu całkowitego & $\%(\mathrm{~m} / \mathrm{m})$ & 0,12 & 0,01 \\
\hline $\begin{array}{l}\text { Zawartość osadów potencjalnych } \\
\text { (po starzeniu termicznym) }\end{array}$ & $\%(\mathrm{~m} / \mathrm{m})$ & 0,16 & 0,02 \\
\hline
\end{tabular}




\section{Wyniki badań}

Zestawione próbki paliw poddawano następnie długotrwałemu przechowywaniu. W tym celu próbki, w luźno zakręconych naczyniach szklanych, umieszczono w suszarce laboratoryjnej w temperaturze $80^{\circ} \mathrm{C}$. Po upływie 3 miesięcy przeprowadzono analizę paliw bazowych i uszlachetnionych po starzeniu.

Wyniki badań (wraz z niepewnością pomiaru) dla próbek paliwa bazowego i uszlachetnionego PA po starzeniu w ciągu 3 miesięcy w temperaturze $80^{\circ} \mathrm{C}$ przedstawiono w tablicy 3 .

Różnica gęstości paliwa bazowego i paliwa uszlachetnionego pakietem PD1 nie przekracza wartości niepewności metody. Natomiast dla olejów opałowych uszlachetnionych pakietami PD2 i PD3 gęstość paliw w trakcie przechowywania jest mniejsza o $7,6 \div 10,1 \mathrm{~kg} / \mathrm{m}^{3}$ niż w przypadku paliwa bazowego. Analogicznie lepkość próbek paliw uszlachetnionych po okresie przechowywania jest mniejsza niż paliwa bazowego. Różnice lepkości poszczególnych paliw przekraczają wartość niepewności metody. Wpływ pakietów można zatem uznać za korzystny: zastosowane dodatki ograniczają wzrost lepkości paliw w trakcie przechowywania.

Wyniki badań potwierdzają skuteczność dodatków: zawartość osadów jest znacząco niższa dla próbek zawierających pakiety w porównaniu z paliwem bazowym. Można zauważyć, że skuteczność działania jest zróżnicowana: największy wpływ w zakresie zapobiegania wytrącaniu osadów wykazuje pakiet zawierający dodatek detergentowo-dyspergujący A. Podobnie pakiety dodatków wykazują pozytywne działanie w zakresie dyspergowania osadów, tj. liczba separacji faz jest znacząco niższa dla paliw uszlachetnionych w porównaniu z paliwem bazowym. W przypadku paliwa uszlachetnionego pakietem dodatków PD1 (bez dyspergatora) pozytywny wpływ wynika najprawdopodobniej z obecności dodatku detergentowego w składzie pakietu.

Wyniki badań (wraz z niepewnością pomiaru) dla próbek paliwa bazowego i uszlachetnionego PB po starzeniu w ciągu 3 miesięcy w temperaturze $80^{\circ} \mathrm{C}$ przedstawiono w tablicy 4 .

Różnice temperatury płynięcia, gęstości oraz zawartości osadów dla paliwa bazowego i paliw uszlachetnionych nie przekraczają wartości niepewności stosowanych metod. W zakresie lepkości obserwuje się wyraźny wpływ dodatków: paliwa uszlachetnione charakteryzują się niższą lepkością niż paliwo bazowe. Zatem - podobnie jak dla paliwa PA - również w tym przypadku zastosowane pakiety ograniczają wzrost lepkości paliw w trakcie przechowywania.

Ocena skuteczności działania pakietów w zakresie zapobiegania wytrącaniu osadów nie jest możliwa, gdyż w badanych paliwach - zarówno uszlachetnionych, jak i bazowym - po okresie przechowywania nie stwierdzono obecności osadów.

Tablica 3. Wyniki badania paliw po starzeniu w temp. $80^{\circ} \mathrm{C}$ w ciągu 3 miesięcy (paliwo bazowe PA)

\begin{tabular}{|l|c|c|c|c|}
\hline Pakiet dodatków & - & PD1 & PD2 & PD3 \\
\hline Poziom dozowania $[\mathrm{mg} / \mathrm{kg}]$ & - & 1500 & 3500 & 2500 \\
\hline \multicolumn{5}{|c|}{ Wyniki badań } \\
\hline Gęstość w temperaturze $20^{\circ} \mathrm{C}\left[\mathrm{kg} / \mathrm{m}^{3}\right]$ & $939,2 \pm 1,5$ & $938,0 \pm 1,5$ & $929,1 \pm 1,5$ & $931,6 \pm 1,5$ \\
\hline Lepkość w temperaturze $100^{\circ} \mathrm{C}\left[\mathrm{mm}^{2} / \mathrm{s}\right]$ & $15,93 \pm 0,68$ & $14,64 \pm 0,65$ & $10,02 \pm 0,51$ & $11,50 \pm 0,56$ \\
\hline Temperatura płynięcia $\left[{ }^{\circ} \mathrm{C}\right]$ & $-20 \pm 4,3$ & $-20 \pm 4,3$ & $-22 \pm 4,3$ & $-21 \pm 4,3$ \\
\hline Zawartość osadów w próbce średniej $[\%(m / m)]$ & $2,76^{1)}$ & $1,30^{1)}$ & $0,13 \pm 0,08$ & $0,25 \pm 0,11$ \\
\hline SN (liczba rozdziału faz) & $13,5 \pm 6,5$ & $1,0 \pm 1,9$ & $2,6 \pm 3,0$ & $0,1 \pm 0,7$ \\
\hline
\end{tabular}

${ }^{1)}$ Norma PN ISO 10307 Oznaczanie zawartości osadów określa precyzję dla wartości granicznej nieprzekraczającej 0,5\% ( $\left./ \mathrm{m} / \mathrm{m}\right)$, w przypadku której niepewność wynosi 0,15 .

Tablica 4. Wyniki badania paliw po starzeniu w temp. $80^{\circ} \mathrm{C}$ w ciągu 3 miesięcy (paliwo bazowe PB)

\begin{tabular}{|l|c|c|c|c|}
\hline Pakiet dodatków & - & PD1 & PD2 & PD3 \\
\hline Poziom dozowania $[\mathrm{mg} / \mathrm{kg}]$ & - & 1500 & 3500 & 2500 \\
\hline \multicolumn{5}{|c|}{ Wyniki badań } \\
\hline Gęstość w temperaturze $20^{\circ} \mathrm{C}\left[\mathrm{kg} / \mathrm{m}^{3}\right]$ & $969,5 \pm 1,5$ & $968,9 \pm 1,5$ & $970,3 \pm 1,5$ & $970,9 \pm 1,5$ \\
\hline Lepkość w temperaturze $100^{\circ} \mathrm{C}\left[\mathrm{mm}^{2} / \mathrm{s}\right]$ & $105,0 \pm 3,23$ & $88,01 \pm 2,74$ & $95,22 \pm 2,95$ & $90,81 \pm 2,82$ \\
\hline Temperatura płynięcia $\left[{ }^{\circ} \mathrm{C}\right]$ & $4 \pm 4,3$ & $0 \pm 4,3$ & $4 \pm 4,3$ & $3 \pm 4,3$ \\
\hline Zawartość osadów w próbce średniej $[\%(\mathrm{~m} / \mathrm{m})]$ & $0,01 \pm 0,02$ & $0,01 \pm 0,02$ & $0,01 \pm 0,02$ & $0,01 \pm 0,02$ \\
\hline SN (liczba rozdziału faz) & $5,9 \pm 4,4$ & $3,8 \pm 3,6$ & $3,9 \pm 3,6$ & $2,0 \pm 2,6$ \\
\hline
\end{tabular}

${ }^{1)}$ Norma PN ISO 10307 Oznaczanie zawartości osadów określa precyzję dla wartości granicznej nieprzekraczającej 0,5\% $(\mathrm{m} / \mathrm{m})$, w przypadku której niepewność wynosi 0,15 . 
Paliwa uszlachetnione wykazują natomiast lepsze właściwości dyspergujące (niższa wartość liczby rozdziału faz SN) niż paliwo bazowe, zwłaszcza paliwo uszlachetnione pakietem zawierającym dodatek detergentowo-dyspergujący B.

\section{Podsumowanie i wnioski}

1. Stwierdzono, że nowe formulacje pakietów dodatków do paliw pozostałościowych nie wpływają negatywnie na badane parametry ciężkiego oleju opałowego w trakcie długotrwałego przechowywania w podwyższonej temperaturze.
2. Uszlachetnione paliwa mogą być eksploatowane w warunkach zakładów energetycznych, co eliminuje konieczność wprowadzania skomplikowanych rozwiązań technicznych w instalacjach podawania ciężkiego oleju opałowego, umożliwiających dozowanie pakietu on-line.

Prosimy cytować jako: Nafta-Gaz 2017, nr 2, s. 105-108, DOI: 10.18668/NG.2017.02.05

Artykuł nadesłano do Redakcji 21.11.2016 r. Zatwierdzono do druku 16.01.2017 r.

Artykuł powstał na podstawie pracy statutowej pt. Wpływ nowych formulacji dodatków na właściwości paliwa w trakcie przechowywania - praca INiG - PIB na zlecenie MNiSW; nr zlecenia 0053/16, nr archiwalny 4101-53/16.

\section{Literatura}

[1] Çelik M., Solmaz H., Serdar Yücesu H.: Examination of the effects of organic based manganese fuel additive on combustion and engine performance. Fuel Processing Technology 2015, vol. 139, s. 100-107.

[2] Duda A., Baranik M.: Stabilność paliw pozostałościowych i metody jej badania. Czesść 1. Nafta-Gaz 2008, nr 5, s. 322-328.

[3] Duda A., Łaczek T.: Stabilność paliw pozostałościowych i metody jej badania. Czesść 2. Nafta-Gaz 2009, nr 7, s. 556-560.

[4] Duda A., Ziemiański L., Żak G., Markowski J.: Zastosowanie dodatków dyspergujacych $w$ celu poprawy stabilności paliw pozostałościowych. Przemysł Chemiczny 2016, t. 95 , nr 2, s. 290-292.

[5] Fayyazbakhsh A., Pirouzfar V.: Investigating the influence of additives-fuel on diesel engine performance and emissions: Analytical modeling and experimental validation. Fuel 2016, vol. 171, s. 167-177.

[6] Jang S.H., Choi J.H.: Comparison of fuel consumption and emission characteristics of various marine heavy fuel additives. Applied Energy 2016, vol. 179, s. 36-44.

[7] Sajeevan A.C., Sajith V.: Synthesis of stable cerium zirconium oxide nanoparticle - Diesel suspension and investigation of its effects on diesel properties and smoke. Fuel 2016, vol. 183, s. $155-163$.

[8] Shaafi T., Sairam K., Gopinath A., Kumaresan G., Velraj R.: Effect of dispersion of various nanoadditives on the performance and emission characteristics of a CI engine fuelled with diesel, biodiesel and blends - A review. Renewable and Sustainable Energy Reviews 2015, vol. 49, s. 563-573.
[9] Stelmachowski P., Kopacz A., Legutko P., Indyka P., Wojtasik M., Ziemiański L., Żak G., Sojka Z., Kotarba A.: The role of crystallite size of iron oxide catalyst for soot combustion. Catalysis Today 2015, vol. 257, s. 111-116, DOI: 10.1016/j. cattod.2015.02.018.

[10] Zhi-Hui Zhang, Rajasekhar Balasubramanian: Influence of an iron-based fuel-borne catalyst on physicochemical and toxicological characteristics of particulate emissions from a diesel engine. Applied Energy 2015, vol. 146, s. 270-278.

[11] Żak G., Duda A., Bujas C.: Wpływ pakietu dodatków do ciężkiego oleju opałowego na właściwości paliwa w trakcie dtugotrwatego przechowywania. Nafta-Gaz 2015, nr 4, s. 250-255.

\section{Patenty}

[12] Patent P.404521 - Ziemiański L., Żak G., Duda A. i in.: Wielofunkcyjny dodatek do olejów opałowych, 2013.

[13] Patent P.412034 - Ziemiański L., Żak G., Duda A. i in.: Uniwersalny pakiet dodatków do olejów opałowych.

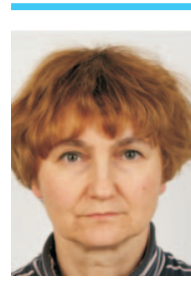

Mgr inż. Anna DUDA

Specjalista badawczo-techniczny w Zakładzie Paliw i Procesów Katalitycznych.

Instytut Nafty i Gazu - Państwowy Instytut Badawczy ul. Lubicz $25 \mathrm{~A}$

31-503 Kraków

E-mail: anna.duda@inig.pl

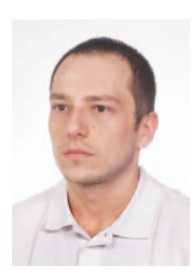

Mgr Kamil BERDECHOWSKI

Starszy specjalista badawczo-techniczny w Zakładzie Paliw i Procesów Katalitycznych.

Instytut Nafty i Gazu - Państwowy Instytut Badawczy ul. Lubicz 25A

31-503 Kraków

E-mail:kamil.berdechowski@inig.pl
Dr Grażyna ŻAK

Adiunkt w Zakładzie Dodatków i Nowych

Technologii Chemicznych.

Instytut Nafty i Gazu - Państwowy Instytut Badawczy ul. Lubicz 25 A

31-503 Kraków

E-mail: grazyna.zak@inig.pl 